\title{
Congenital tracheal stenosis caused by a new tracheal ring malformation
}

\author{
Juan L. Antón-Pacheco, MD, PhD, ${ }^{\mathrm{a}}$ María López, MD, ${ }^{\mathrm{a}}$ Cecilia Moreno, $\mathrm{MD},{ }^{\mathrm{a}}$ and Gerardo Bustos, MD, PhD, ${ }^{\mathrm{b}}$ \\ Madrid, Spain
}

Congenital tracheal stenosis (CTS) is an uncommon airway malformation typically caused by complete tracheal rings with no posterior membranous pars. The extension of the stenosis may include only a few rings or involve the entire trachea. ${ }^{1}$ Bryant and Morales ${ }^{2}$ recently described a new type of CTS caused by a completely distinct tracheal ring, referred to as "corkscrew" trachea.

We report what we believe is the second case of this novel type of CTS, and we describe our management plan.

\section{CLINICAL SUMMARY}

A full-term neonate showed stridor with moderate respiratory distress soon after birth. These symptoms were related to the position of the head, in such a way that stridor and respiratory distress were more severe when the baby turned her head to the right. Flexible bronchoscopy $(2.8$ $\mathrm{mm}$ in diameter) showed a short stenosis of approximately $3 \mathrm{~mm}$ in diameter in the cervical trachea. The morphologic features of the stenotic ring were similar to those described

From the Division of Pediatric Surgery and Pediatric Airway Unit ${ }^{\mathrm{a}}$ and Division of Neonatology, ${ }^{\mathrm{b}}$ Hospital Universitario 12 de Octubre, Madrid, Spain.

Disclosures: Authors have nothing to disclose with regard to commercial support.

Received for publication Jan 17, 2011; revisions received Jan 31, 2011; accepted for publication Feb 18, 2011; available ahead of print April 14, 2011.

Address for reprints: Juan L. Antón-Pacheco, MD, PhD, c/Vallehermoso 20, $7^{\circ} \mathrm{A}$ izda, Madrid 28015, Spain (E-mail: janton.hdoc@salud.madrid.org).

J Thorac Cardiovasc Surg 2011;141:e39-40

$0022-5223 / \$ 36.00$

Copyright (C) 2011 by The American Association for Thoracic Surgery doi:10.1016/j.jtcvs.2011.02.022 for the corkscrew-type tracheal stenosis (Figure 1, A). The distal trachea and main bronchi were explored and showed no anomalies. Computed tomography of the chest confirmed the bronchoscopic findings and ruled out tracheal extrinsic compression and other associated malformations (Figure 2).

Because of the anatomic characteristics of the stenosis, an endoscopic treatment was attempted first. This comprised balloon dilation and diode laser therapy. Improvement was not consistent, and subcutaneous emphysema with bilateral pneumothorax developed after the laser procedure. These complications resolved with appropriate treatment, and the patient was scheduled for surgical treatment.

The lesion was approached through a low cervical collar incision. Exposure of the anterior surface of the trachea showed a short stenosis $(<1 \mathrm{~cm})$ that could be easily identified externally. Nevertheless, intraoperative flexible bronchoscopy was performed to confirm the location of the stenosis. Resection of the stenosis and tracheal reconstruction, with a tension-free end-to-end anastomosis using interrupted absorbable sutures, were then performed. Ventilation of the patient during the surgical procedure was initially done by means of an orotracheal tube positioned above the stenosis and intubating the distal trachea through the operative field when the trachea was transected. The orotracheal tube was advanced distally when the posterior part of the anastomosis was completed.

The postoperative course was uneventful. The patient was extubated on postoperative day 4 and discharged in
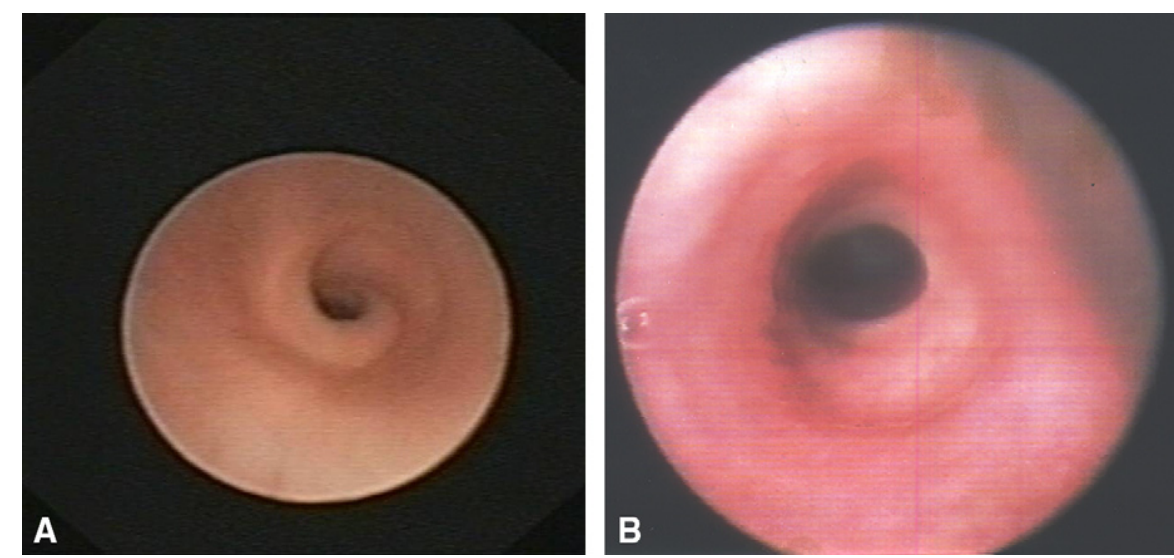

FIGURE 1. A, Bronchoscopic view of the stenotic trachea. The corkscrew type of tracheal ring can be observed. B, Bronchoscopic view of a CTS caused by complete tracheal rings. 


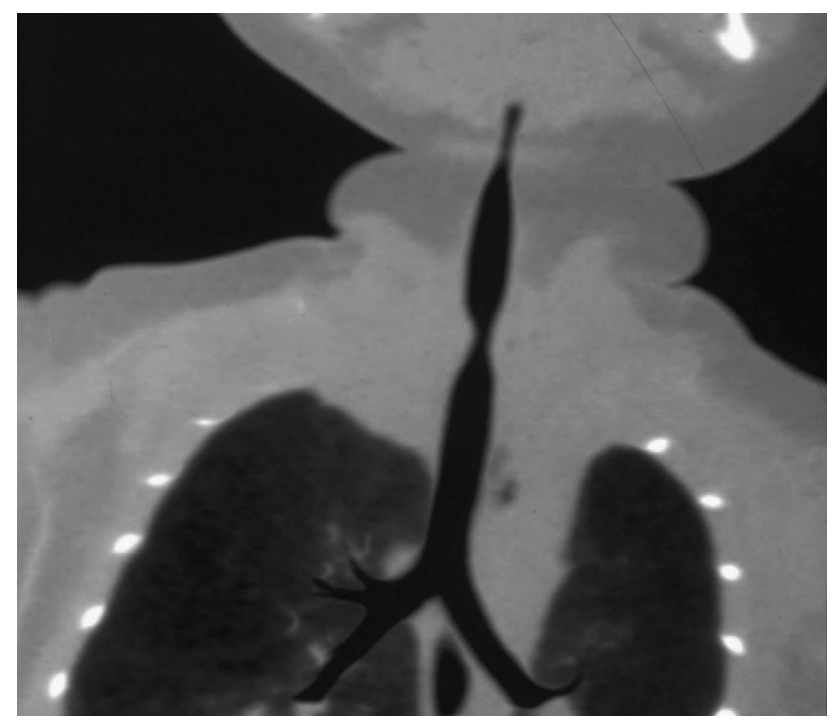

FIGURE 2. Chest CT scan. Stenotic lesion in the upper trachea.

good condition 2 weeks after surgery. At 3 months followup, the patient is asymptomatic from a respiratory standpoint, and a follow-up bronchoscopy showed excellent healing of the trachea with a widely patent anastomosis.

\section{DISCUSSION}

Although complete tracheal rings are usually responsible for CTS, other ring or cartilage anomalies, such as a complete tracheal cartilaginous sleeve, also may be responsible. ${ }^{3}$ Corkscrew trachea is a novel type of congenital tracheal ring anomaly described recently. ${ }^{2}$ Our case seems to be the second described of this new type of CTS. The anatomic features of this ring are unique: It is not a complete tracheal ring, and the membranous posterior portion is twisted upward, substantially reducing the tracheal lumen (Figure 1). These special characteristics explain why stridor is not continuous and is related to the head position, in contrast with what happens in CTS caused by complete tracheal rings.
When a flexible bronchoscopy with spontaneous ventilation was performed, we observed no tracheal collapse with the respiratory movements; thus, malacia was ruled out. On the other hand, airway extrinsic compression was not observed on chest computed tomography.

Because there is some experience with endoscopic treatment as the preferred type of management in patients with CTS, ${ }^{4}$ we tried dilation and laser therapy first. As in the case described by Bryant and Morales ${ }^{2}$ the result was not satisfactory. It seems that surgical management is still the treatment of choice in patients with symptomatic CTS. Short stenosis, less than one third of the tracheal length, can be managed safely with resection and tracheal reconstruction with end-to-end anastomosis. Because of the cervical location of the stenosis, ventilation during the procedure can be easily performed by intubating the distal trachea through the operating field, making cardiopulmonary bypass unnecessary. Tracheal surgery principles, established by Mulliken and Grillo 5 more than 40 years ago, apply as much in children as in adults. The goal of a tension-free tracheal anastomosis with an ample lumen must be achieved to obtain a sustained good result.

\section{CONCLUSIONS}

CTS can be caused by different types of ring anomalies. Corkscrew trachea seems to be a new morphologic type that should be included in the standard CTS categories. ${ }^{1,3}$

\section{References}

1. Cantrell JR, Guild HG. Congenital stenosis of the trachea. Am J Surg. 1964;108: 297-305.

2. Bryant R, Morales DL. Corkscrew trachea: a novel type of congenital tracheal stenosis. Ann Thorac Surg. 2009;87:1923-5.

3. Antón-Pacheco JL, Cano I, Comas J, Galleti L, Polo L, García A, et al. Management of congenital tracheal stenosis in infancy. Eur J Cardiothorac Surg. 2006;29: 991-6.

4. Othersen HB Jr, Hebra A, Tagge EP. A new method of treatment for complete tracheal rings in an infant: endoscopic laser division and balloon dilation. J Pediatr Surg. 2000;35:262-4

5. Mulliken JB, Grillo HC. The limits of tracheal resection with primary anastomosis: further anatomical studies in man. J Thorac Cardiovasc Surg. 1968;55: 418-21. 